\title{
GRADUATES ON LABOUR MARKET IN ROMANIA. PRECARITY OR RESILIENCE?
}

\author{
Roxana Hatos \\ Research Centre for Competitiveness and Sustainable Development, Faculty of Economic \\ Sciences, University of Oradea, Oradea, Romania \\ rhatos@uoradea.ro
}

\begin{abstract}
Young people on the labor market is a topical issue both in academia and in the latest European and national policies. Young graduates are no exception. They invest in education and want a better match of their studies with the job. Some analyzes performed on AMIGO data and data performed with economics graduates help us to analyze the existing situation. The conclusions show us significant differences in terms of income, in terms of the field of study as well as the mismatch with the graduated field. In terms of gender, there are differences in job satisfaction, with men being more likely to reach leadership positions than women.
\end{abstract}

Keywords: labour market; young people; unemployment; labour market integration; education.

JEL classification: I26; J01; J08

\section{Introduction}

In the dynamics of preparing students for the labor market, higher education institutions play a major role. They have been called upon in recent decades to prepare students for the labor market with skills necessary for the labor market. This approach has intensified especially through the expansion of higher education and the Bologna process which has somewhat redefined the way education is viewed in terms of the transition from school to the active life of graduates (Schomburg and Teichler, 2011). In this regard, research was conducted to provide valuable information about the employment skills of graduates. As Furlong and others have shown, the instability for young people entering the labor market is led by the processes of social, political and economic changes.

Simple international statistical comparisons, starting from national indicators of labor market participation, can reveal groups of countries with similar sizes and dynamics of the same indicators, which suggests relatively similar institutional or institutionalized realities on the respective labor markets. Overeducation can be seen as a loss of society in terms of resources invested. It can bring lower income to the individual and lower opportunities to engage in appropriate positions. Although studies show that this phenomenon of asymmetry has not increased in the last 20 years, the explanation for why it is so widespread is being studied and analyzed. Although the transition from school to work can be seen in terms of individual participation in economic activity or employment, by age groups, economic domains, areas of residence and sex, occupations, production, income, etc. . often, these explanatory criteria are combined.

Cite as:

Hatos, R., 2021. Graduates on Labour Market in Romania. Precarity or Resiliece?. Oradea Journal of Business and Economics, 6(2), pp. 21- 28.

http://doi.org/10.47535/19910jbe126 
Although the transition from school to work is a natural phenomenon and assumed at the individual level, the success of the transition is largely due to the social and economic context of the country. Romania is no exception (Mursa, et al., 2015) from having an imperfect picture of the insertion of young people on the labor market. Concerns for the efficiency of the labor market for young people are materialized in measures and policies that the state must apply to increase the employment rate and investment in human capital.

\section{Literature Review}

Beyond the important differences by country in terms of the transition of young people from school to work, the literature considers an extremely complex concept of the neoliberal economy defined as precariousness in the labor market. We find in the literature the concept of precariousness as being strictly related to the insecurity of the 21 st century on the labor market. As is well known, neoliberal deregulation of the labor market has led to a higher degree of insecurity manifested in many jobs over a period of time, part-time or insecure in Europe (Standing, 2011).

Over-education can also be seen in terms of earnings and job search. (Quintano et al., 2008). The likelihood of being over-educated can be explained by gender, education, the channels used to enter the labor market, the location of the job or the labor sector. According to the study, women seem to be the most affected when it comes to over-qualification, as they have qualifications above the level of the position held. The study by García-Aracil and Van der Velden (2008) shows that jobs with higher requirements in terms of skills and complexity are better paid. Also, high skills requirements increase job satisfaction. Overeducation and over-skills in the labor market severely affect incomes. Studies show that the relationship between labor market income and asymmetry is strongly influenced by an unnoticed heterogeneity (Mavromaras et al., 2013). The results of studies conducted on graduates show that the asymmetry of skills expresses a professional path with many disadvantages (Liu et al., 2016). Matching the first job has an important effect at the beginning of your career.

Over-education can bring the individual lower incomes and a lack of employment opportunities in qualifying positions. Also, for society, overeducation is a loss in terms of resources invested for education (Caroleo and Pastore, 2015).

The issue of the transition from school to employment is not specific to our country, but exist in all countries and take on increasingly complex dimensions, in the economic framework based on knowledge. The impact of a generation that suffers from the effects of exclusivity will act together with the political and social evolution that will shape Europe in the coming years (Dimian, 2014).

Although there is a rich literature on the school-labor transition in developed countries, for post-communist countries the literature for this topic is lacking. Analyzing the entry patterns of higher education graduates from several former communist countries (Zamfir et al., 2020) it is argued that much of the variation between countries in the school-labor transition can be attributed to differences in labor market circumstances.

An analysis conducted on data from Romania (Mursa et al., 2015) aimed to demonstrate that the high unemployment rate among young people in Romania is caused by the difficulties that arise in the process of transition from the education system (school) to the labor market (labor). Although the transition from school to work is a natural phenomenon and assumed at the individual level, the success of the transition is largely due to the social and economic context of the country. Romania is no exception to having an imperfect picture of the insertion of young people on the labor market. Concerns for the efficiency of the labor market for young people are materialized in measures and policies that the state must apply to increase the employment rate and investment in human capital. The analyses show that 
the under-employment is not explained by any demographic variables (Hatos and Saveanu, 2016).

Differences related to finding a job and the risk of remaining unemployed are analyzed by various age categories and level of education. As expected (Simionescu and Naros, 2019) the young unemployed with higher education who previously worked are $1.3 \%$ less likely to remain unemployed compared to the young unemployed with higher education who did not worked before. Therefore, young people who have recently graduated, with no experience into the labor market, need more support to better integrate. A highly segmented labor market usually favors a mismatch between supply and demand, significantly limiting functional flexibility and market resilience to macroeconomic shocks. (Dobre et al., 2011).

Equal access to education is one of the fundamental human rights. However, numerous studies show that educational disparities persist between different groups in many countries Atkinson and Messy (2012). Educational inequalities are on the agenda of policy makers in many countries, as they affect the life chances of individuals and contribute to the perpetuation of social disadvantages. In many cases, children from disadvantaged communities have lower school results and grow up without gaining the skills needed in the labor market. It is argued (Zamfir, 2017) that rural-urban educational inequalities determine the polarization of human capital, producing long-term labor market segmentation. Also, the institutional performance of Romanian counties (Dragoman, 2011) does not completely correlate with regional wealth; but regional disparities and the mechanisms used to mitigate inequalities must be taken into account in the public debate on further decentralization.

The participation of individuals in education is an important factor for their access to future opportunities, especially to labor market opportunities. Moreover, a significant number of studies show that education is one of the most influential factors that explains the amount of resources available to individuals in all their life cycles. In this context, reducing school dropout and increasing the share of people who are graduates of higher education are national objectives for Romania (Zamfir and Mocanu, 2016).

The social and economic changes of the Romanian society have affected the labor market, leading to unprecedented imbalances between the supply and demand in the labor market also in terms of both quantitatively and qualitatively (Deaconu and Rasca, 2014). The relationship between universities and the labor market is an important subject of analysis in terms of the graduate's transition to the labor market. Studies (Stanciu and Banciu, 2012) show that diplomas are considered valuable by employers, but graduates have better theoretical knowledge than practical training in the field. Some studies (Mocanu et al., 2014) focus on the needs of employers of skills by assessing their perception of the importance of different skills required of higher education graduates, as well as satisfaction with the level of the various competencies. Overcoming the current situation, increasing social involvement in universities and establishing appropriate strategies would promote employability and economic development.

Given this complex situation we focus in our analyses to reflect some of the aspects related to income and how the job match the diploma of the graduates in to the labour market.

\section{Methodology}

The analyzed data focuses on both indirect data set and direct data collected about graduates. We used the quarterly databases of the AMIGO survey (Household Labor Force Survey), the Romanian version of the LFS (Labor Force Survey) from 2018.

Details on the sampling scheme, estimation errors and survey in general can be found in the INSSE report on the 2018 AMIGO survey: 
https://insse.ro/cms/files/Rapoarte\%20de\%20calitate/Amigo/RO AMIGO rap calitate Ro m 2018.pdf

Number of records in the database: 228114. Since the selection unit is the household and the data collection is done repeatedly from the same household according to a certain algorithm, we identified unique individuals in the database: 58,229 cases. We selected the most recent records for analysis.

The second set of analyzed data is sampled by graduates of the Faculty of Economic Sciences. The tracer survey was conducted by the technique of indirect survey of the selfadministered online questionnaire in the period 2015-2016, with 419 answers.

\section{Data Analysis and Discussion}

In the first part we intend to see if the income is significantly different in relation with specialization that youth graduated.

Table 1: Graduated specialization and income decile (standardized chi-square residues)

\begin{tabular}{|l|r|r|r|r|r|r|r|r|r|r|}
\hline & 1 & 2 & 3 & 4 & 5 & 6 & 7 & 8 & 9 & 10 \\
\hline $\begin{array}{l}\text { Teaching studies and } \\
\text { educational sciences }\end{array}$ & $-1,6$ & $-0,9$ & 0,9 & $-1,3$ & $-1,3$ & -1 & 2,6 & 2 & 0,4 & $-0,8$ \\
\hline Humans, languages, arts & $-0,2$ & $-1,9$ & $-0,6$ & 2,4 & 1,5 & $-0,7$ & $-0,7$ & 0,9 & $-0,4$ & $-0,6$ \\
\hline $\begin{array}{l}\text { Social sciences, business } \\
\text { and law }\end{array}$ & $-0,2$ & 1,5 & 1,8 & $-1,8$ & 0,3 & 0,3 & $-0,6$ & 0,6 & 0,9 & $-2,1$ \\
\hline $\begin{array}{l}\text { Sciences, mathematics } \\
\text { computer sciences }\end{array}$ & 1,6 & 1,5 & 0,4 & 0,3 & $-0,4$ & 0,4 & 0,8 & $-0,5$ & $-2,3$ & $-0,7$ \\
\hline $\begin{array}{l}\text { Engineering, production and } \\
\text { constructions }\end{array}$ & 1,8 & 0,8 & $-1,1$ & $-1,5$ & 2,4 & $-0,5$ & 0,1 & $-0,7$ & $-0,4$ & $-0,1$ \\
\hline Agricultures and vets & -1 & $-1,4$ & 1,1 & 0,4 & $-0,7$ & $-0,5$ & $-1,1$ & 1,6 & $-0,6$ & 1,5 \\
\hline Medical and wellbeing & $-0,4$ & $-0,7$ & $-1,5$ & 2 & $-2,1$ & 0,3 & $-0,3$ & $-2,3$ & 1,8 & 2,2 \\
\hline Services & $-0,9$ & $-0,2$ & 0,2 & -2 & 1 & 0 & 1,5 & 0,6 & $-0,1$ & $-0,4$ \\
\hline Unknown & $-0,9$ & $-0,8$ & $-1,6$ & $-0,3$ & 0,2 & 0,8 & $-1,4$ & $-0,5$ & 1,9 & 1,6 \\
\hline
\end{tabular}

Source: Our statistical processing based on AMIGO dataset

The interpretations of the analyzes for the income situation show us that in the income decile of the different specializations, where we have the coefficient 2, we have a significant concentration of incomes in that decile on specializations. The concentration of high incomes is found in the last decades for the specializations: "medical and welfare", "science, mathematics, computers" and "social sciences, business and law". This indicates to us that for these specializations, the incomes registered on the last deciles are higher than the average of the decile. For the domains where we have the coefficient less than 0 for the income deciles then we have in that decile registered cases less than the general average of the respective decile.

The limits of this analysis are given by the data set that does not provide the variables needed to evaluate underemployment or overemployment. Another limitation is the fact that we do not know if he works in the field of graduated specialization. 


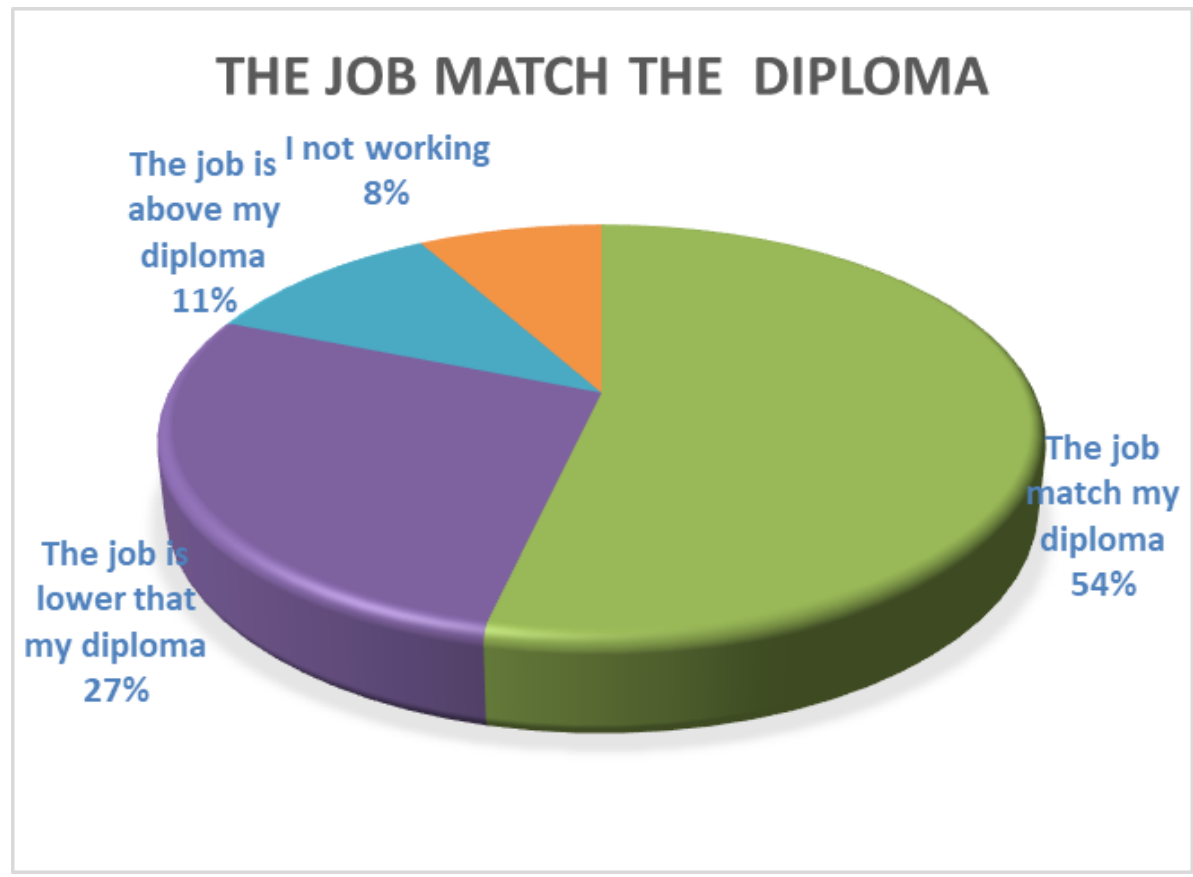

Figure 1: The job match the diploma

We have as the result that our graduates are more likely to have a match, $53,6 \%$, between the workplace and the qualification. Also $27.5 \%$ declare that they have a workplace that is lower to their qualification.

We know from previous analyzes that job satisfaction is significantly associated with both gender (men have higher satisfaction) and the position held (the highest levels of job satisfaction are manifested by those in management positions).

Given the documented existence of discrimination in the workplace against women, the question arises as to whether higher levels of job satisfaction in men are explained by the fact that men are more present in leadership positions.

As expected, the relationship between the two variables is significant, the presence of men in leadership positions being significantly higher than that of women ( $p$ (chi-square) $<0.01$ ). 


\section{Position held by gender}

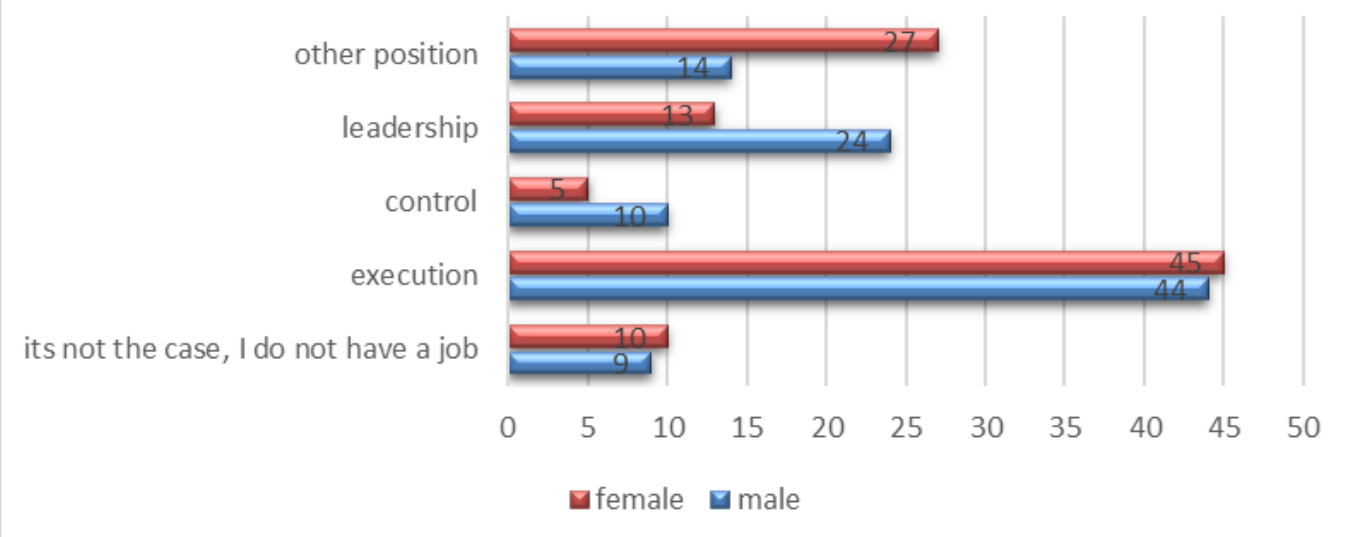

Figure 2: Position held by gender

Therefore, it is plausible to assume that the relationship between gender and job satisfaction is explained, at least in part, by the fact that men are more likely than women to be promoted to leadership positions.

\section{Conclusion}

Young people on the labor market are a widely debated topic in a contemporary socioeconomic context. The integration process of young graduates on the labor market is inhomogeneous and with uncertain and lasting results. The data analyzed by us in this paper come to emphasize the precariousness reflected by this approach of theirs. Their lack of experience but also the relatively long time spent in education are just a few aspects that make them vulnerable. The first set of analyzes at national level presents graduates with very different incomes, although they are all graduates of higher education. Some professions are characterized as having above average incomes. The concentration of high incomes is found for the specializations: "medical and welfare", "science, mathematics, computers" and "social sciences, business and law". This aspect emphasizes the socioeconomic differences given by the field in which the graduate is preparing to work. Training in a certain field brings him predictable income. The analyzes performed with the data collected from the economics graduates are no exception when it comes to their studies and the job occupied. We have as the result that our graduates are more likely to have a match, $53,6 \%$, between the job and the qualification. Also $27.5 \%$ declare that they have a job that is lower to their qualification. The mismatch between the graduate field and the job, especially at the beginning of the career, may be due, to the existing imbalances between institutions and the labor market. Relationship between gender and job satisfaction is explained, at least in part, by the fact that men are more likely than women to be promoted to leadership positions.

The conclusions of the study underline that Romanian universities should take the students, and after that the graduates, into account in order to fulfill their role of partner in medium business, to adapt to its growing requirements, to strengthen its position vis-à-vis competitors working in the field of education in and to contribute more actively to facilitating the immediate integration of their graduates into the profession for which they have been 
trained. Our results have a practical approach in order to find the best ways in supporting our graduates for better integration into the labour market.

\section{Acknowledgment:}

This research received financial support through the project "SmartDoct - High quality programs for doctoral students and postdoctoral researchers of the University of Oradea to increase the relevance of research and innovation in the context of regional economy", ID / Project code: 123008, co-financed by the European Social Fund through the Human Capital Operational Program 2014-2020.

\section{References}

Atkinson, A. and F. Messy, 2012. Measuring Financial Literacy: Results of the OECD / International Network on Financial Education (INFE) Pilot Study. OECD Working Papers on Finance, Insurance and Private Pensions, No. 15, OECD Publishing. http://dx.doi.org/10.1787/5k9csfs90fr4-en.

Caroleo, F. E. and Pastore, F., 2015. Overeducation: A Disease of the School-to-Work Transition System. IZA Discussion Paper, No. 9049, Available at SSRN: https://ftp.iza.org/dp9049.pdf [data accesarii: 15.08.2021]

Mursa, G., Munteanu-Gurgu, C., Musetescu, R. C., and Paun, V. C., 2015. The transition from school to labour market and youth unemployment in Romania. Transformations in Business and Economics, 14 (2A), pp. 432-442.

Dimian, G.C., 2014. Labour Market and Educational Mismatches in Romania. Procedia Economics and Finance, 10, pp. 294-303. https://doi.org/10.1016/S2212-5671(14)00305-0. Dobre, M., Ailenei D., and Cristesc A., 2011. Regional Distribution of Discrimination Forms in the Labour Market in Romania. Romanian Journal of Regional Science, 5(2), pp. 53-64. Dragoman, D., 2011. Regional Inequalities, Decentralisation and the Performance of Local Governments in Post-Communist Romania. Local Government Studies, 37(6), pp. 647-669. https://doi.org/10.1080/03003930.2011.623010.

García-Aracil, A., and Van der Velden, R., 2008. Competencies for young European higher education graduates: labor market mismatches and their payoffs. Higher Education, 55, pp. 219-239. https://doi.org/10.1007/s10734-006-9050-4.

Hatos, R., and Saveanu, T., 2016. Are economic studies graduate under-employed? A skill mismach study, Oradea Journal of Business and Economics, 1(1) pp. 27-37, https://doi.org/10.47535/19910jbe003.

Liu, K., Salvanes, K.G, and Sørensen, E. Ø., 2016. Good skills in bad times: Cyclical skill mismatch and the long-term effects of graduating in a recession. European Economic Review, 84, pp. 3-17, https://doi.org/10.1016/i.euroecorev.2015.08.015.;

Mavromaras, K., McGuinness, S., O'Leary, N., Sloane, P. and Wei, Z., 2013. Job Mismatches and Labour Market Outcomes: Panel Evidence on University Graduates. Economic Record, 89: pp. 382-395. https://doi.org/10.1111/1475-4932.12054;

Mocanu, C., Zamfir, A.M. Maer-Matei, M.M., 2014. Skills And Employability Of Higher Education Graduates From Romania And Bulgaria: The Employers' Perspective, Education and Educational Research. Procedia Economics and Finance, 10, pp. 294-303, https://doi.org/10.5593/sgemsocial2014/B13/S3.106.

Quintano, C., Castellano, R., and D'Agostino, A., 2008. Graduates in economics and educational mismatch: the case study of the University of Naples 'Parthenope'. Journal of Education and Work,21(3), pp. 249-271, https://doi.org/10.1080/13639080802214118. 
Schomburg and Teichler, 2011. Employability and Mobility of Bachelor Graduates in Europe: Key Results of the Bologna Process, Publisher: Sense Publishers, Editor: SCHOMBURG, Harald and TEICHLER, Ulrich, https://doi.org/10.1007/978-94-6091-570-3.

Stanciu, S., and Banciu, V., 2012. Quality of Higher Education in Romania: Are Graduates Prepared for the Labour Market? Procedia - Social and Behavioral Sciences, 69, pp. 821827, https://doi.org/10.1016/i.sbspro.2012.12.004.

Standing C., and Kiniti, S., 2011. How can organizations use wikis for innovation? Technovation, 31 (7), pp. 287-295, https://doi.org/10.1016/i.technovation.2011.02.005.

Zamfir, A.-M., 2017. Urban-Rural Educational Inequalities and Human Capital Polarization in Romania. Revista Romaneasca Pentru Educatie Multidimensionala, 9(3), pp. 157-165. Retrieved from https://lumenpublishing.com/journals/index.php/rrem/article/view/174 [10.08.2021]

Zamfir, A.-M., Militaru, M., Mocanu C., and Lungu, E. O., 2020. School-to-work transition of higher education graduates in four European countries. Compare: A Journal of Comparative and International Education, 50(1), pp. 36-52. https://doi.org/10.1080/03057925.2018.1493572.

Zamfir, Ana-Maria; Mocanu Cristina, 2016. Exploring Educational Inequalities in Romania. Romanian Journal for Multidimensional Education / Revista Romaneasca pentru Educatie Multidimensionala. 8(1), p171-180. http://dx.doi.org/10.18662/rrem/2016.0801.10

\section{Bionote}

Roxana Hatos, Ph.D., is a researcher at the Faculty of Economics, Research Center for Competitiveness and Sustainable Development. Her PhD thesis was regarding: Youth on the labour market. Opportunities and difficulties of insertion. Some of her preoccupations are related to: youth on the labour market and skills mismatch. 